\title{
Research into Factors Impeding Weibo Marketing of Chinese Commercial Banks
}

\author{
Pang Shizhang ${ }^{a}$, Ju Xiaofeng ${ }^{b}$ \\ School of management Harbin institute of technology \\ apoem0303@126.com, bjuxf@hit.edu.cn,
}

Keywords: technical economy; commercial bank; Weibo marketing; inhibitors; adopt intention.

\begin{abstract}
As the improvement of living standards, People's demand of financial services and information has also increased. However, the lack and uneven distribution of bank outlets make it still inconvenient. To satisfy their needs, many banks are providing the information and services on their Weibo platforms. Based on the current state bias theory and rational choice theory, this paper introduces privacy-related factors and establishes a structural equation model. In order to verify the theoretical model, a questionnaire survey method was used to generate receipt data, and a total of 398 valid samples were collected. The results of model verification show that perception benefit and perceived risk based on the current state bias theory affect the adoption of financial services on commercial banks' microblogging platforms. The privacy protection belief can be used as an uncertainty cost to introduce the current status deviation theory. The adjustment experience of the Internet experience is quite obvious. This study focuses on the factors that hinder the commercial bank microblogging financial promotion and has certain theoretical and practical significance.
\end{abstract}

\section{Introduction}

With increasing popularity of Weibo (China's Twitter), its commercial and marketing value has been in the limelight. More and more enterprises have incorporated Weibo marketing as a part of their overall marketing. Commercial banks are no exception. At present, four major state-owned commercial banks and more than 10 listed stock-holding banks in China have launched their Weibo accounts to operate their banking service brands on Weibo, the brand-new social media platform. Some foreign-invested banks, urban commercial banks and so on have also followed suit, spreading their brands on Weibo.

The market potential of the Weibo user group is compelling. There have been many successful Weibo marketing cases, which have provided a series of marketing strategies. Commercial banks should not only learn from these strategies, but also try to find out strategies which can bring better marketing effects. This research can not only deepen readers' understanding of users' acceptance of Weibo marketing of commercial banks, but also enrich the theory of technology acceptance to some extent. Therefore, the theoretical and practical significance of this research is obvious.

Abroad, social media marketing has been a general research interest. Foreign scholars have investigated this issue mainly through three aspects: 1 ) information quality of social media posts; 2) consumers' acquisition of corporate information via social media; 3) consumer acceptance.

Palaniappan Shamala et al. (2017) argued that online information quality can be judged from the dimension of accuracy, data size, completeness, objectivity, credibility and verifiability [1]. Nadia Arif et al. (2018) observed that medical information quality of commercial websites is far inferior to that of non-profit websites [2]. By analyzing different EU members, Celia Boyer (2013) found major quality problems with the online information serving the public and challenges posed by random spreading to private data, and that these problems, not just existing in developing countries, are equally serious in developed countries [3]. Research performed by Lisete de Vries et al. (2012) suggested that brand posts on brand fan pages can improve the popularity of brand posts, but negative and positive comments under the posts have a significantly positive and negative influence on popularity of brand posts, respectively [4]. Maryam Ghasemaghaei et al. (2015) pointed out a strong 
correlation between online information quality and consumer satisfaction and that the respondent sources and types play a moderating role in the correlation [5]. Amir Hassan Zadeh et al. (2015) put forward that point models can favorably describe the relationship between influence and brand popularity in online social networks [6]. In view of the major advantage of social networks in directly attracting consumers through brand posts, Carsten D. Schultz (2017) held the idea that information vividness and interactivity of information are key factors deciding marketing quality [7]. Wagner et al. (2017) thought that, in posting information on social media, brands tend to information posting methods which can bring a negative influence rather than those which have a positive influence [8]. Research carried out by Yongfu He (2018) suggested that retailers can lead consumers' perception of information quality and influence consumers' online product choices by displaying of sales and stock level information [9]. According to findings of Safdar Hussain et al. (2017), electronic world of mouth of brands is a major factor deciding consumers' online information adoption, and improvement of electronic world of mouth mainly relies on social interaction, economic incentive and self-value strengthening [10].

\section{Modeling, Questionnaire Design and Data Collection}

In this section, a questionnaire is designed based on behavioral characteristics of commercial banks' Weibo marketing. A questionnaire survey is conducted among Weibo users concerning their opinions on commercial banks' Weibo marketing. Statistical software, including SPSS and AMOS, is used for data processing and analysis. The structural dimensions influencing consumers' acceptance of commercial banks’ Weibo marketing are examined, and their credibility is verified.

\subsection{Model Construction}

Technology acceptance has been much investigated in the field of information system. A series of classical models, including theory of reasoned action (TRA), technology acceptance model (TAM) and unified theory of acceptance and use of technology (UTAUT) have emerged. Improvements have been achieved by research into these classical models. This research attempts to study consumers' behavioral transformation from the traditional financial model to the social media financial model from the perspective of status quo bias theory and rational choice theory. Rational choice selection can be used as a measure of comprehensive benefits by weighing both benefits and costs. Based on the calculation results, a better decision can be made. So it is with the financial model selection. It is necessary to clarify benefits of transforming to a new financial model and how much costs it takes. In this way, the negative and positive influence new financial model adopted can be both examined.

This research chooses information relevance and information credibility as two factors which can influence users' perception of the social media financial model. When faced with a new financial model, users might reject the new financial model because of their loss-aversion psychology and perceived costs incurred by network applications and their unfamiliarity with relevant procedures. Privacy is an issue of great concern to the financial field. Therefore, this research incorporates privacy protection conviction in status quo bias theory and explores whether privacy issues can be a part of status quo bias under the financial background. Commercial and financial service consumers have been long concerned about their privacy. Hence, privacy is also an issue not to be ignored by financial services provided via social media. Meanwhile, different user groups pay different degrees of attention to privacy. This results in their different degrees of intention to transform to a new financial model. Since financial service provided via social media involve not only finance, but also Internet transmissions, users' adoption behavior is likely to be influenced by their Internet use experience. Considering this, Internet use experience is adopted by this paper as an adjusting variable, which serves to adjust the relationship among antecedent variables, intermediate variables and dependent variables. This can help gain a better understanding of different use behaviors of financial services provided via social media by user groups with different Internet use experience. In this research, status quo theory, privacy protection theory and rational choice theory are combined to explore factors hindering users' adoption of the social media financial model and to verify the 
adjusting role of Internet use experience.

Based on the above analysis, this research attempts to build a social media financial service adoption model with obstructing factors taken into account. Status quo bias theory and rational choice theory constitute the basic theoretical framework of the model. The model structure consists of four parts: 1) antecedent variables, which are mainly obstructing factors based on status quo bias theory; 2) independent variables, which mainly refer to perceived benefits and perceived costs, and the adjusting variable (Internet use experience) in the middle part; 3) dependent variable in the right, which is users' adoption intention; and 4) control variables. The model structure is illustrated in Fig. 1:

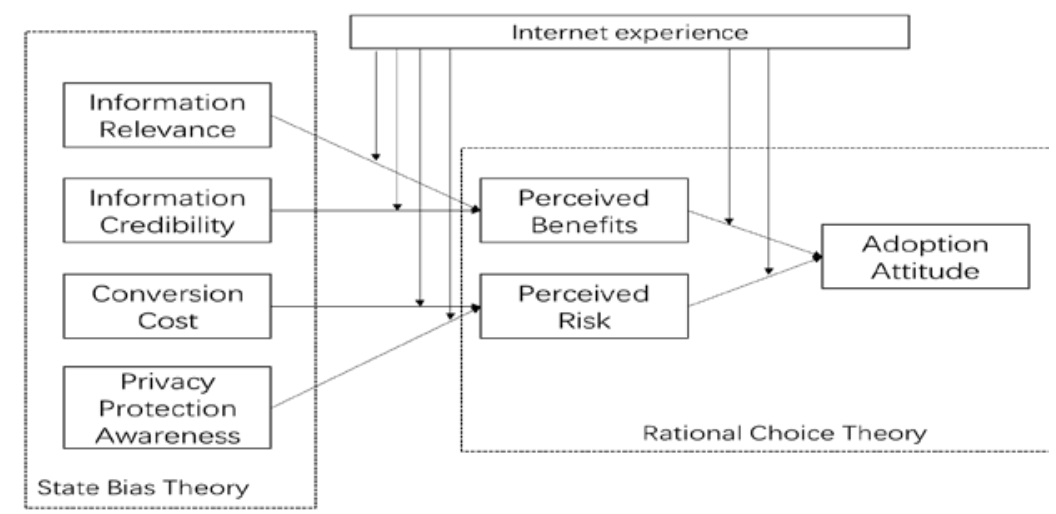

Fig. 1 Theoretical model

\subsection{Model Construction}

According to the above analysis and research of the model and combining the main research questions of this paper, the following hypotheses are made revolving around the model built above:

\subsubsection{Hypotheses of the direct influence}

H1: Users' perceived benefits have a positive influence on commercial banks’ Weibo marketing model.

H2: Users’ perceived risks have a negative influence on commercial banks’ Weibo marketing model.

H3: Information relevance has a positive influence on users' perceived benefits of commercial banks' Weibo marketing model.

H4: Information credibility has a positive influence on users' perceived benefits of commercial banks' Weibo marketing model.

H5: Cost of service transformation has a positive influence on users' perceived risks of commercial banks' Weibo marketing model.

H6: Privacy protection conviction has a positive influence on users' perceived risks of commercial banks’ Weibo marketing model.

\subsubsection{Hypotheses of the adjusting role}

There are risks and uncertainties existing in online commodities or services. These risks and uncertainties are mainly resulted from lack of legal standards, misleading advertising, extra charge, poor service quality, etc. Because of these risks, it is hard for consumers to correctly judge the cost and value of the product they are going to buy [11]. Therefore, consumers hope they can know more about the product supplier. The information can provide more guidance for their future purchase decision-making. This suggests that relevant experience can play an important role in alleviating perceived risks of consumers as an information source [12]. After evaluating perceived benefits of commercial banks' Weibo marketing service, users will decide whether to adopt the service or not. Assume that users have rich Internet use experience, they will have more resources and abilities to cope with online transactions and get more familiar with online transaction procedures. In this way, these users will show a higher intention to adopt Weibo marketing. The following hypotheses are 
made concerning the adjusting role of Internet use experience:

H1a: Users' Internet use experience has a positive adjusting role on the relationship between users' perceived benefits and adoption intention of commercial banks' Weibo marketing.

H2a: Users' Internet use experience has a positive adjusting role on the relationship between users' perceived risks and adoption intention of commercial banks' Weibo marketing.

H3a: Users' Internet use experience has a positive adjusting role on the relationship between information relevance and users perceived benefits of commercial banks' Weibo marketing.

H4a: Users' Internet use experience has a positive adjusting role on the relationship between information credibility and users' perceived benefits of commercial banks' Weibo marketing.

H5a: Users' Internet use experience has a negative adjusting role on the relationship between users' cost of service transformation and perceived risks of commercial banks' Weibo marketing.

H6a: Users' Internet use experience has a negative adjusting role on the relationship between users' privacy protection conviction and perceived risks of commercial banks’ Weibo marketing.

\subsection{Questionnaire design}

Questionnaire design is an essential part of empirical research in this paper, which can lay a solid foundation for significance analysis of model hypotheses. The questionnaire survey of this paper mainly consists of three parts. Part 1 is about basic information of respondents. Part 2 presents respondents' cognition of traditional bank financial model. Part 3 shows respondents' cognition and adoption of commercial bank' Weibo marketing. Seven-point Likert scale is employed by this research to allow respondents to score different things or objects in the form of agreeing or disagreeing. The seven dimensions include "strongly disagree”, "disagree”, "basically disagree”, "neither disagree or agree", "basically agree", "agree" and "strongly disagree". Details of the seven-point Likert scale are shown in Table 1:

\subsection{Data collection}

Responders of this survey are a group of ordinary people with certain Internet use experience. This survey is mainly conducted through two methods. In the first method, survey is organized on wjx.cn with questionnaires delivered online and different respondents invited to finish the questionnaires. Responders participating in the survey are promised to have an opportunity to participate in a lucky draw. In the second method, the print questionnaires are delivered nearby the supermarkets or other stores. When a questionnaire is given to one respondent, the online medical care service is introduced to him or her and relevant puzzlements the responder has about the questionnaire are cleared. In total, 513 copies of questionnaires are collected. Excluding the unfinished questionnaires, questionnaires finished obviously irrationally, and questionnaires failing to do trap questions correctly, there are 451 valid questionnaires, registering an effective recovery rate of $87.9 \%$.

\subsubsection{Descriptive statistics of samples}

As mentioned above, 398 valid questionnaires are collected. In order to gain an in-depth understanding of responders, this research statistically analyze the sample indexes from the perspective of responders' sex, gender, educational background and Internet use experience, respectively. It is found that the data distribution of respondents' sex, age, educational background and Internet use experience in this survey generally comply with the data distribution of the 41st Statistical Report on China Internet Development released by the China Internet Network Information Center (CNNIC). This suggests that the samples adopted by this research are basically consistent with distribution characteristics of Chinese netizens.

\subsubsection{Normal distribution testing of sample data}

Bentler et al. (1987) pointed out that a prerequisite for structural model analysis is the sample data set should meet the Gaussian distribution [20]. Though Smart PLS shows research results are in line with abnormal distribution, the results can be better if under normal distribution. One condition for sample data to meet normal distribution is that measurement indexes of various components, after 
passing the descriptive test, should control the absolute value their skewness to be smaller than 2 and the absolute value of their kurtosis to be smaller than 2. This research adopts SPSS for statistical analysis of the sample data. The major output indexes include mean, maximum, minimum, standard deviation, skewness and kurtosis. Analysis results suggest that the maximum absolute value of skewness is 1.708, which is smaller than 2, while the maximum absolute value of kurtosis is 2.170, which is smaller than 5 . Therefore, the survey data of this research are basically in line with normal distribution, meaning that structural equation analysis can be conducted.

\section{Structural equation analysis}

After the above data verification, the data analysis software, Smart PLS, is used to analyze the model. Based on the partial least squares (PLS), the software is mainly applied to verification of exploratory and conceptual models. PLS requires the number of samples to be higher than the number of latent variables in the model by three folds. The sample data adopted by this research is up to this requirement. In view of the general steps of structural equation model analysis, this research attempts to analyze the measurement model and the structural model. The measurement model is mainly responsible for verifying credibility and validity of sample data; while the structural model for verifying model hypotheses.

\subsection{Credibility test}

Similar to pre-survey credibility analysis, factor loading, Cronbachs Alpha, composite credibility and average variance extraction (AVE) are usually adopted as measurement indexes of credibility. The following figure shows the credibility test results. As one notices from it, the factor loading of all components is higher than 0.75; their Cronbachs $\alpha$ coefficient and comprehensive credibility coefficient are all higher than 0.7; their AVE is all close to or higher than 0.6. This means the measurement model has a high credibility.

\subsection{Validity test}

Validity test of sample data is mainly conducted from two aspects. First, correlation coefficient test of various components. Second, analysis of cross factor loading. Analysis results suggest that the correlation coefficient between different components is all lower than the arithmetic square root of the corresponding AVE. This suggests that relevant components of the model possess a high judgment validity. Besides, the factor loading coefficient of every measurement item on the corresponding component is higher than that on the other components. Meanwhile, the loading coefficient on the corresponding component is either higher than or close to 0.7. This indicates a favorable convergence validity of components.

\subsection{Basic model verification}



Fig. 2 Schematic diagram of basic model verification results

Basic model verification mainly examines the influence of antecedent variables on independent 
variables as well as influence of independent variables on dependent variables. In other words, it mainly verifies whether hypotheses ranging from $\mathrm{H} 1$ to $\mathrm{H} 6$ are substantiated. To facilitate observation, the following scheme of basic model results is formulated on the basis of the above table. See Fig. 2. “***” denotes significance on the confidence level of 0.01 ; “**” denotes significance on the confidence level of 0.05 ; “*” denotes significance on the confidence level of 0.1 .

\subsection{Complete model test}

Table 3. Complete model verification results



Fig. 3 Schematic diagram of complete model verification results

The complete research model covers all influencing factors. On the basis of the basic model, the adjusting role of the Internet use experience is included. The complete research model mainly examines the significance level of the Internet use experience's adjusting role. The complete model verification results are shown in Table 3. 
To better demonstrate the verification results to readers, the basic model results are presented in the form of a schematic diagram. See Fig. 3. “***” denotes significance on the confidence level of 0.01 ; “**” denotes significance on the confidence level of 0.05 ; “*” denotes significance on the confidence level of 0.1 . In Fig. 3, the full line means the path coefficient is significant; while the imaginary line means the path coefficient is insignificant.

\subsection{Analysis of structural model verification results}

The above two model analyses provide solid support for part of hypotheses, while some hypotheses are left unsubstantiated. Table 4 presents the substantiation results of every hypothesis:

Table 4. Substantiation of hypotheses

\begin{tabular}{|c|c|c|}
\hline No. & Hypotheses & Substantiation \\
\hline H1 & $\begin{array}{l}\text { Users’ perceived benefits have a positive influence on commercial banks' Weibo } \\
\text { marketing model. }\end{array}$ & Substantiated \\
\hline H2 & $\begin{array}{c}\text { Users’ perceived risks have a negative influence on commercial banks’ Weibo } \\
\text { marketing model. }\end{array}$ & Substantiated \\
\hline H1a & $\begin{array}{l}\text { Users' Internet use experience has a positive adjusting role on the relationship } \\
\text { between users’ perceived benefits and adoption intention of commercial banks' } \\
\text { Weibo marketing. }\end{array}$ & Substantiated \\
\hline $\mathrm{H} 2 \mathrm{a}$ & $\begin{array}{c}\text { Users' Internet use experience has a positive adjusting role on the relationship } \\
\text { between users’ perceived risks and adoption intention of commercial banks' Weibo } \\
\text { marketing. }\end{array}$ & Substantiated \\
\hline H3 & $\begin{array}{l}\text { Information relevance has a positive influence on users’ perceived benefits of } \\
\text { commercial banks’ Weibo marketing model. }\end{array}$ & Substantiated \\
\hline $\mathrm{H} 4$ & $\begin{array}{l}\text { Information credibility has a positive influence on users’ perceived benefits of } \\
\text { commercial banks’ Weibo marketing model. }\end{array}$ & Substantiated \\
\hline НЗа & $\begin{array}{l}\text { Users’ Internet use experience has a positive adjusting role on the relationship } \\
\text { between information relevance and users perceived benefits of commercial banks' } \\
\text { Weibo marketing. }\end{array}$ & Substantiated \\
\hline $\mathrm{H} 4 \mathrm{a}$ & $\begin{array}{l}\text { Users' Internet use experience has a positive adjusting role on the relationship } \\
\text { between information credibility and users' perceived benefits of commercial banks' } \\
\text { Weibo marketing. }\end{array}$ & Substantiated \\
\hline H5 & $\begin{array}{l}\text { Cost of service transformation has a positive influence on users’ perceived risks of } \\
\text { commercial banks' Weibo marketing model. }\end{array}$ & Substantiated \\
\hline H6 & $\begin{array}{l}\text { Privacy protection conviction has a positive influence on users' perceived risks of } \\
\text { commercial banks' Weibo marketing model. }\end{array}$ & Substantiated \\
\hline H5a & $\begin{array}{c}\text { Users' Internet use experience has a negative adjusting role on the relationship } \\
\text { between users' cost of service transformation and perceived risks of commercial } \\
\text { banks' Weibo marketing. }\end{array}$ & Opposite \\
\hline H6a & $\begin{array}{c}\text { Users' Internet use experience has a negative adjusting role on the relationship } \\
\text { between users' privacy protection conviction and perceived risks of commercial } \\
\text { banks' Weibo marketing. }\end{array}$ & Unsubstantiated \\
\hline
\end{tabular}

\subsection{Result analysis}

The six hypotheses of the direct influence proposed in this paper have been substantiated. Meanwhile, the perceived benefits variance is explained by $26.7 \%$; the perceived risks variance is explained by $29.5 \%$; the perceived benefits and risks explain the adoption intention variance by $36.6 \%$. All this proves that the model has a favorable explanatory power. The components of the model constitute major influencing factors of the independent variable. The adjusting role of users' Internet use experience is reflected in six aspects. After the adjusting role of users' Internet use experience is introduced, the explaining degree of perceived benefits, perceived risks and adoption intention in the model is improved by $14.8 \%, 7.9 \%$ and $13.6 \%$, respectively. Among the hypotheses, $\mathrm{H} 1 \mathrm{~m}$ to $\mathrm{H} 4 \mathrm{~m}$ are all substantiated; the adjusting role of users' Internet use experience stipulated in $\mathrm{H} 5 \mathrm{~m}$ is opposite to the verification results; the adjusting role of users" internet use experience in $\mathrm{H} 6 \mathrm{~m}$ is not substantiated. Taken as a whole, the basic model hypotheses have all been substantiated. 
In other words, most hypotheses in this paper provide solid support for the adjusting role of users' Internet use experience. Therefore, the model setting in this paper is verified to be feasible.

The latest financial information, authoritative market information and promotional activities posted on commercial banks' Weibo account can make consumers realize existence of Weibo marketing behaviors and their potential benefits. This will motivate users to gradually withdraw from the traditional financial participation model.

Transformation cost is incurred by users' transferring from one financial participation model to the other. To involve in financial activities on social media, users need to spend time and energy learning social media operations first. Meanwhile, users are faced with perpetual influence of online financial services in other aspects. Transformation cost has a positive influence on perceived risks of online financial services, thus impeding adoption of commercial banks' Weibo marketing. In order to alleviate the obstructing role of transformation cost, commercial banks can highlight convenience and efficiency of their online financial services in their Weibo account. In this way, users' perceived transformation cost will be lowered, which will in turn attract more clients to use financial services provided on Weibo.

Privacy is an important consideration of the Internet era. In financial behaviors, privacy mainly refers to personal identity information and financial account information. These privacy issues have gained increasing attention from the public. In traditional financial services, personal information is transmitted orally, via print documents or internal networks. This gives clients a strong sense of privacy protection. Online financial services, on the contrary, are provided through network communication, which is inevitably associated with a high degree of uncertainty and wide spreading. Therefore, users will perceive more risks while receiving online financial service. The more the perceived risks are, the less likely the users will be to turn to online financial services. Privacy protection conviction can arouse users' concerns about privacy security in financial services provided via Weibo. It can be adopted as an uncertain cost, which might result in users' refusal to change from traditional financial service to online financial service on Weibo.

Users' Internet use experience is an accumulation of users' experience in exposing themselves to the Internet. It can not only enrich users' knowledge of network products and service, but also forge users' positive toward to network products and service. However, because of the specific relationship between perceived risks and adoption intention, users' Internet use experience plays a negative adjusting role. As users' Internet use experience increases, the influence of perceived risks on adoption intention strengthens, and users are more likely to perceive information relevance and credibility on Weibo account. Also, with improvement of users' Internet use experience, the influence of transformation cost weakens. Therefore, users' Internet use experience plays a negative role in adjusting the relationship between transformation cost and perceived risks. However, data suggest that the adjusting role is positive, meaning that users' Internet use experience plays a positive adjusting role, which is opposite to the hypothesis.

\section{Conclusion}

To sum up, this paper combines relevant research questions and theories to build a commercial banks' Weibo financial service adoption model with status quo bias theory and rational choice theory as the theoretical basis. Based on the model, factors impeding users' adoption of commercial bank's Weibo financial service are examined. In the Weibo financial service adoption model, the impeding factors coming from the traditional financial model based on status quo bias theory are adopted as antecedent variables, perceived risks and benefits as intermediate variables, and users' Internet use experience as the adjusting variable. Meanwhile, the privacy protection conviction is introduced by the model to status quo bias theory at an attempt to further develop the theory. In order to verify validity and credibility of the model, a questionnaire survey is conducted. The data acquired from the survey are used to empirically verify the impeding factors and the adjusting role of impeding factors. Results show that this research can contribute to recognition and verification of factors obstructing users' adoption of the Weibo financial service model. Therefore, the model built in this paper can 
provide marketing suggestions for commercial banks in launching financial service on Weibo and attracting more users.

\section{References}

[1] Shamala P, Ahmad R, Zolait A, et al. Integrating information quality dimensions into information security risk management (ISRM) [J]. Journal of Information Security and Applications, 2017, 36: $1-10$.

[2] Arif N, Ghezzi P. Quality of online information on breast cancer treatment options [J]. The Breast, 2018, 37: 6-12.

[3] BOYER C. The Internet and Health: International Approaches to Evaluating the Quality of Web-Based Health Information [M]. e Health: Legal, Ethical and Governance Challenges. Springer. 2013: 245-274.

[4] De Vries L, Gensler S, Leeflang P S H. Popularity of brand posts on brand fan pages: An investigation of the effects of social media marketing [J]. Journal of interactive marketing, 2012, 26(2): 83-91.

[5] Ghasemaghaei M, Hassanein K. Online information quality and consumer satisfaction: The moderating roles of contextual factors-A meta-analysis [J]. Information \& Management, 2015, 52(8): 965-981.

[6] Zadeh A H, Sharda R. Modeling brand post popularity dynamics in online social networks [J]. Decision Support Systems, 2014, 65: 59-68.

[7] Schultz C D. Proposing to your fans: Which brand post characteristics drive consumer engagement activities on social media brand pages? [J]. Electronic Commerce Research and Applications, 2017, 26: 23-34.

[8] Wagner T F, Baccarella C V, Voigt K I. Framing social media communication: Investigating the effects of brand post appeals on user interaction [J]. European Management Journal, 2017, 35(5): 606-616.

[9] He Y, Oppewal H. See How Much We’ve Sold Already! Effects of Displaying Sales and Stock Level Information on Consumers’ Online Product Choices [J]. Journal of Retailing, 2017.

[10] Hussain S, Guangju W, Jafar R M S, et al. Consumers' online information adoption behavior: Motives and antecedents of electronic word of mouth communications[J]. Computers in Human Behavior, 2018, 80: 22-32.

[11] MITCHELL V W. Problems and risks in the purchasing of consultancy services [J]. Service Industries Journal, 1994, 14 (3): 315-339.

[12] BENNETT R, H RTEL C E, MCCOLL-KENNEDY J R. Experience as a moderator of involvement and satisfaction on brand loyalty in a business-to-business setting 02-314R [J]. Industrial Marketing Management, 2005, 34 (1): 97-107.

[13] Zeng, X., \& Wang, Y. (2008). Empirical studies of consumers' attitude towards mobile message advertising. Consumer Economics, 24(6), 81-84.

[14] Bhattacherjee A, Sanford C. Influence processes for information technology acceptance: An elaboration likelihood model [J]. MIS quarterly, 2006: 805-825.

[15] POLITES G L, KARAHANNA E. Shackled to the Status Quo: The Inhibiting Effects of Incumbent System Habit, Switching Costs, and Inertia on New System Acceptance [J]. MIS Quarterly, 2012, 36 (1): 21-42.

[16] PAVLOU P A, CHELLAPPA R K. The role of perceived privacy and perceived security in the 
development of trust in electronic commerce transactions [J]. Information System Research, 2001, 11 18-36.

[17] LIANG H, XUE Y. Online Health Information Use by Disabled People: the Moderating Role of Disability [M]. Thirty Fourth International Conference on Information Systems. 2013: 1-16.

[18] MEUTER M L, BITNER M J, OSTROM A L, et al. Choosing among alternative service delivery modes: an investigation of customer trial of self-service technologies [J]. Journal of Marketing, 2005, 69 (2): 61-83.

[19] JOHNSTON A C, WARKENTIN M. Fear Appeals and Information Security Behaviors: An Empirical Study [J]. MIS Quarterly, 2010, 34 (3): 549-570.

[20] BENTLER P M, CHOU C-P. Practical issues in structural modeling [J]. Sociological Methods \& Research, 1987, 16 (1): 78-117. 
Table 1

\begin{tabular}{|c|c|c|c|}
\hline Components & symbols & Scale & Sources \\
\hline \multirow{3}{*}{$\begin{array}{l}\text { Information } \\
\text { relevance }\end{array}$} & IR1 & $\begin{array}{l}\text { Information obtained from commercial banks’ Weibo can be } \\
\text { adopted as a reference. }\end{array}$ & $\begin{array}{l}\text { Zeng, X., } \\
(2008)[13]\end{array}$ \\
\hline & IR2 & $\begin{array}{l}\text { Information obtained from commercial banks' Weibo is what I } \\
\text { need in daily life. }\end{array}$ & \\
\hline & IR3 & $\begin{array}{l}\text { I will recommend commercial banks’ Weibo to my friends if they } \\
\text { need it. }\end{array}$ & \\
\hline \multirow{3}{*}{$\begin{array}{l}\text { Information } \\
\text { credibility }\end{array}$} & IC1 & Commercial banks’ Weibo know banking service well & $\begin{array}{l}\text { Bhattacherjee A } \\
\text { (2006)[14] }\end{array}$ \\
\hline & IC2 & Commercial banks' Weibo is reliable. & \\
\hline & IC3 & $\begin{array}{c}\text { Commercial banks’ Weibo can be regarded as an expert in banking } \\
\text { service. }\end{array}$ & \\
\hline \multirow[b]{2}{*}{$\begin{array}{l}\text { Cost of service } \\
\text { transformation }\end{array}$} & CSTT1 & $\begin{array}{l}\text { It is time-consuming to learn a new financial model (such as time } \\
\text { spent to learn or handle banking service). }\end{array}$ & Polites(2012)[15 \\
\hline & CSTT2 & $\begin{array}{l}\text { It is easy for me to learn a new financial model (such as learning or } \\
\text { handling banking service). }\end{array}$ & \\
\hline \multirow{3}{*}{$\begin{array}{l}\text { Privacy risk } \\
\text { vulnerability } \\
\text { conviction } \\
\text { protection }\end{array}$} & PRVCP1 & $\begin{array}{l}\text { I will protect my own privacy while handling financial service in } \\
\text { banks. }\end{array}$ & $\begin{array}{l}\text { Pavlou \& } \\
\text { Chellappa } \\
\text { (2001)[16] }\end{array}$ \\
\hline & PRVCP2 & I will protect my privacy in banks to prevent it from being abused. & \\
\hline & PRVCP3 & $\begin{array}{l}\text { If I handle financial service in banks, it is almost impossible for } \\
\text { others to acquire my personal information. }\end{array}$ & \\
\hline \multirow{4}{*}{$\begin{array}{l}\text { Perceived } \\
\text { benefits }\end{array}$} & PB1 & $\begin{array}{c}\text { Social media accounts of banks can help me learn banks’ latest } \\
\text { service better. }\end{array}$ & $\begin{array}{c}\text { Liang \& } \\
\text { Xue(2013)[17] }\end{array}$ \\
\hline & PB2 & $\begin{array}{l}\text { Social media accounts of banks can help me learn banks' latest } \\
\text { activities better. }\end{array}$ & \\
\hline & PB3 & $\begin{array}{l}\text { Social media accounts of banks can help me learn my bank } \\
\text { account information at any time. }\end{array}$ & \\
\hline & PB4 & $\begin{array}{l}\text { Social media accounts of banks can help me handle my financial } \\
\text { transactions better. }\end{array}$ & \\
\hline \multirow{4}{*}{ Perceived risks } & PR1 & Banks’ social media marketing might be misleading. & $\begin{array}{c}\text { Liang \& } \\
\text { Xue(2013)[17] }\end{array}$ \\
\hline & PR2 & Banks' social media marketing can bring losses to my property. & \\
\hline & PR3 & $\begin{array}{l}\text { Banks' social media marketing can result in my missing of some } \\
\text { key information. }\end{array}$ & \\
\hline & PR4 & $\begin{array}{l}\text { Messages frequently sent to me via banks’ social media can make } \\
\text { me feel nervous. }\end{array}$ & \\
\hline
\end{tabular}




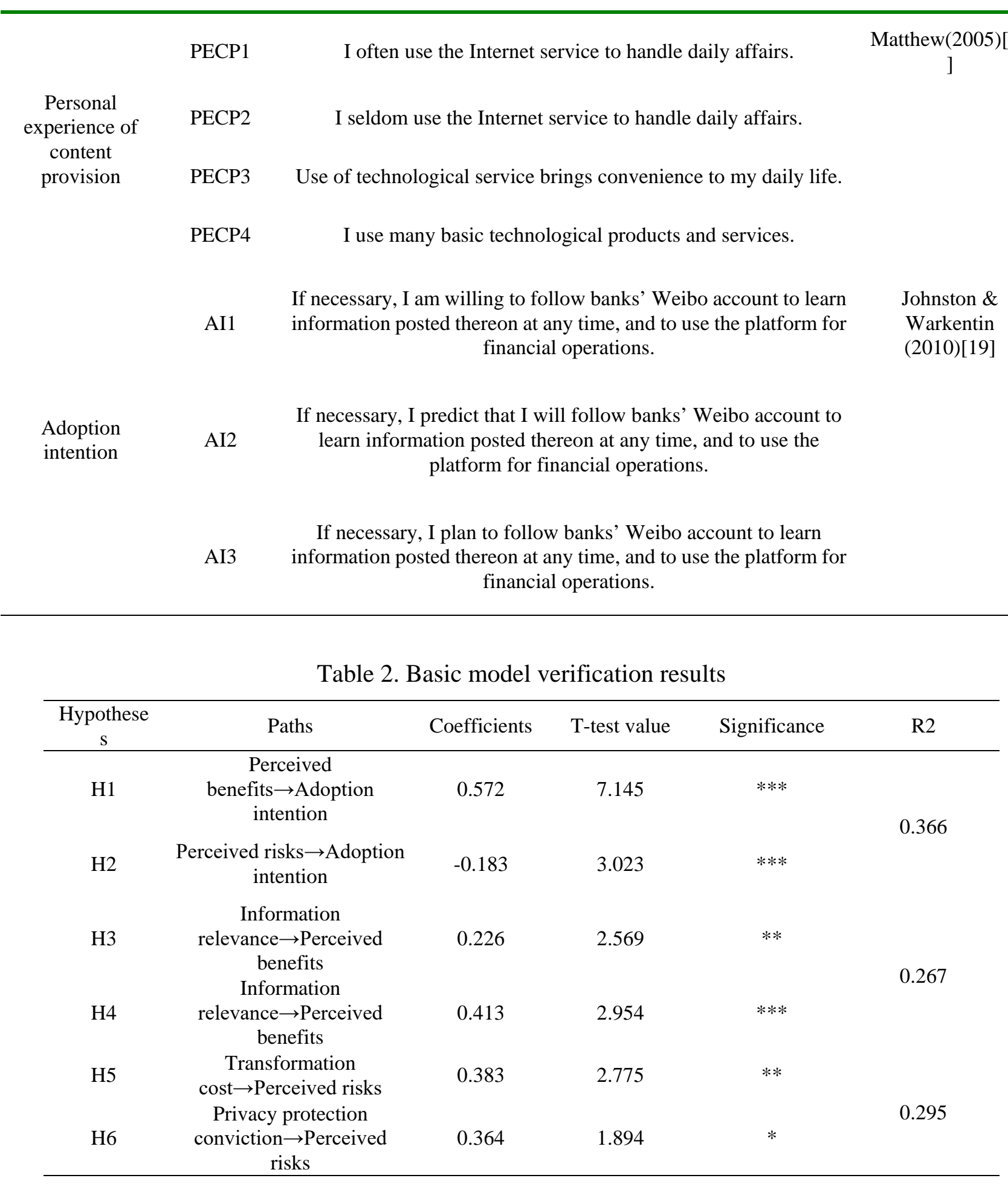

